\title{
Derivations of Correlation and Liquid-Solid Contact Model of Transition Boiling Heat Transfer*
}

\author{
Hiroyasu OHTAKE** and Yasuo KOIZUMI**
}

\begin{abstract}
The correlation of liquid-solid contact fraction in transition boiling was derived by focusing on the dimensionless wall temperature $\theta=\left(T_{w}-T_{C H F}\right) /\left(T_{M H F}-T_{C H F}\right)$. The following correlation was obtained from experimental results for water, R-113 and $\mathrm{LN}_{2}: \Gamma=$ $1.000-0.9120 \theta-0.1343 \theta^{2}$, where $q_{t b}=q_{C H F} \Gamma+q_{M H F}(1-\Gamma)$. In the present model, considering a pseudo-liquid solid contact right after the detachment of a bubble from a liquid-vapor interface, transient heat conduction was analyzed in it three-dimensionally. Liquid-solid contact time and area were determined by the present correlation of the fractions of liquid-solid contact: $\tau_{\text {contact }}=0.3 \Gamma_{t}, A_{\text {wet }}=15 \times 15 \times \Gamma_{a}, \Gamma_{t}=\Gamma_{a}=\Gamma^{0.5}=\left\{1.000-0.9120 \theta-0.1343 \theta^{2}\right\}^{0.5}$. The heat transfer during the wet period was estimated using $q_{w e t}=f\left(\Delta T_{\text {sat }}^{0.8}\right)$. The prediction by the present model was in agreement with the present experimental data for water. Furthermore, a simulation of the rewetting was performed; the experimental results of cooling curves during the rewetting were well reproduced by the transient heat conduction model using the present correlation of transition boiling heat transfer and the present liquid-solid contact model.
\end{abstract}

Key Words: Heat Transfer, Boiling, Heat Conduction, Transition Boiling, Liquid-Solid Contact, Correlation, Model

\section{Introduction}

The heat transfer characteristics of transition boiling are important in nuclear engineering and mechanical engineering, for example, for assessing the reliability of the Emergent Core Cooling System (ECCS) during Lossof-Coolant Accidents (LOCAs) of Light-Water Reactors (LWRs) and analyzing the thermal stability of superconductor magnets and other devices. Thus, many attempts have been made by several investigators to examine the mechanism and models of transition boiling. For example, Berenson ${ }^{(1)}$ pointed out early through many experiments that transition boiling is a combination of unstable film boiling and unstable nucleate boiling, each of which alternately exists at a given location on a heating surface. Kalinin et al. ${ }^{(2)}$ presented a correlation of a liquid-solid contact fraction in transition boiling on the basis of the hypothesis on Ergodic property on liquid-solid contact.

Because of the complexity of mechanism of liquidsolid contact and the difficulty in steady heat transfer ex-

\footnotetext{
* Received 3rd October, 2005 (No. 05-4185)
}

** Department of Mechanical Engineering, Kogakuin University, 2665-1 Nakano-machi, Hachioji-shi, Tokyo 1920015, Japan. E-mail: ohtake@cc.kogakuin.ac.jp periments, however, the heat transfer characteristics are still unresolved. In particular, nucleate and film boiling heat transfers are able to utilize some correlations industrially (for example, Rohsenow's correlation ${ }^{(3)}$ in nucleate boiling and Bromley's equation ${ }^{(4)}$ in film boiling); however, there is no correlation for transition boiling except for a linear correlation between $\mathrm{CHF}$ — critical heat fluxand MHF — minimum heat flux — on any boiling curve. Furthermore, it is pointed out by Witte and Lienhard ${ }^{(5)}$ that there are two possible transition boiling curves: that is, there is hysteresis in transition boiling. On the other hand, Auracher et al. ${ }^{(6)}$ reported that there is no hysteresis in transition boiling for both a well-wetting fluid (FC72) and a fluid (water) with a larger contact angle.

The purpose of this study is to determine the mechanism of transition boiling heat transfer by examining correlations and models. In our previous report, we ${ }^{(7)}$ examined the heat transfer characteristics of transition boiling through steady heat transfer experiments. The correlations of the transition boiling heat transfer were derived from the present experimental data for water. Two models of transition boiling heat transfer were developed and examined using the macrolayer model and liquid-solid contact model, respectively. However, both these models could 
not concur with the experimental data of the transition boiling heat transfer experiments quantitatively: the predictions of transition boiling heat transfer by the macrolayer model underpredicted the previous experimental results significantly; the dependence of the predictions on wall superheat using the liquid-solid contact model differed from that of the experimental data.

The objective of this study is to examine the heat transfer characteristics of transition boiling through steady heat transfer experiments and the use of models. The correlation of transition boiling heat transfer is revised from experimental results for water and other liquids. The modified liquid-solid contact model for transition boiling heat transfer at high wall superheat is developed by taking into account the dependence on wall superheat of liquid-solid contact time and area, and nucleate boiling heat transfer during a wet period. Furthermore, a simulation of rewetting is performed using the present transition boiling correlation.

\section{Nomenclature}

$c:$ specific heat $[\mathrm{J} / \mathrm{kgK}]$

$h:$ heat transfer coefficient $\left[\mathrm{W} / \mathrm{m}^{2} \mathrm{~K}\right]$

$k:$ thermal conductivity $[\mathrm{W} / \mathrm{mK}]$

$L$ : latent heat of vaporization $[\mathrm{J} / \mathrm{kg}]$

$q$ : heat flux $\left[\mathrm{W} / \mathrm{m}^{2}\right]$

$T:$ temperature $[\mathrm{K}]$

$\phi:$ contact angle [degrees]

$\Gamma$ : liquid-solid contact fraction $[-]$

$\Gamma_{a}$ : liquid-solid contact area fraction [-]

$\Gamma_{t}$ : liquid-solid contact time fraction [-]

$\rho:$ density $\left[\mathrm{kg} / \mathrm{m}^{3}\right]$

$\theta:$ dimensionless wall temperature $[-]$

$\sigma:$ surface tension $[\mathrm{N} / \mathrm{m}]$

$\tau:$ period $[\mathrm{s}]$
Subscripts

$$
\begin{gathered}
l: \text { liquid } \\
v: \text { vapor } \\
w: \text { wall }
\end{gathered}
$$

\section{Experimental Apparatus and Procedure}

\subsection{Experimental apparatus}

A schematic diagram of the experimental apparatus used is shown in Fig. 1. Steady heat transfer experiments were conducted using a copper block and saturated water for a pool condition under atmospheric conditions. Details of the test section are illustrated in Fig. 2. As shown in Fig. 2, the test section was $15 \times 15 \times 60 \mathrm{~mm}$ each in length and thickness. The ratio of the heat capacity to the cross sectional area of the heater was $2.2 \times 10^{5} \mathrm{~J} / \mathrm{Km}^{2}$, which was sufficient to maintain the test section in a time-smoothed steady state, as reported by Bui and Dhir ${ }^{(8)}$. Six-electric cartridge-type heaters, $300 \mathrm{~W}$ in total, were embedded on the back surface of the test section. The temperature of

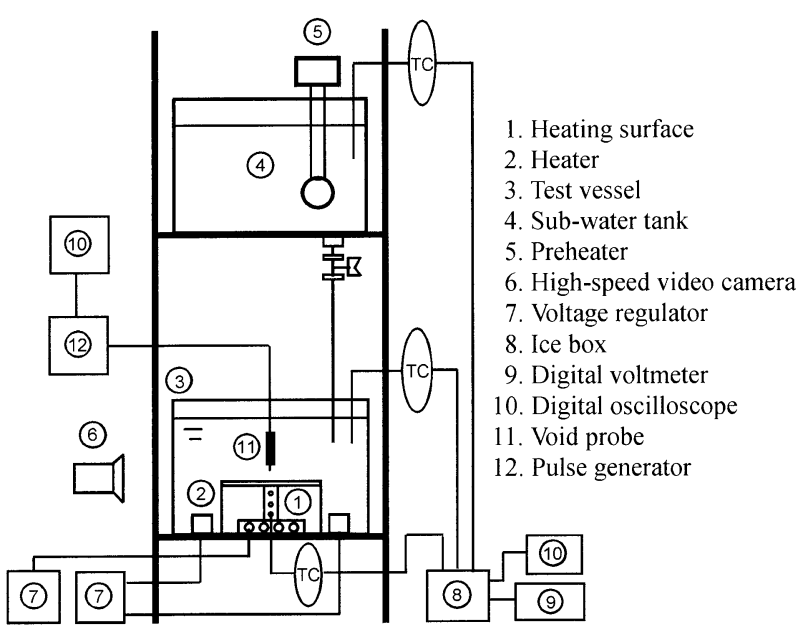

Fig. 1 Experimental apparatus
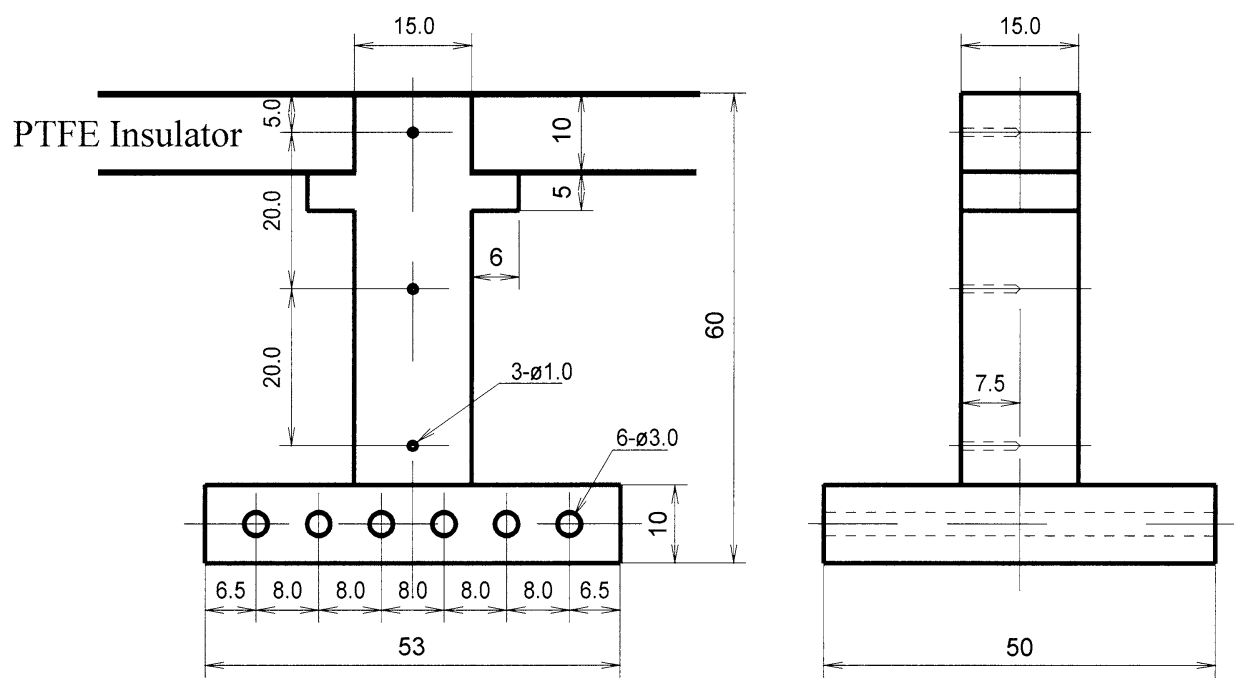

Fig. 2 Details of test section 
the test section was measured at the center of the heater by three thermocouples fitted inside $5,25,40 \mathrm{~mm}$ from the heating surface. The test section was held in a frame of a Teflon plate and insulated thermally by glassy wool except for the top side.

\subsection{Experimental procedure}

Experiments were carried out as follows. Deionized and degassed water was poured in a vessel up to $20 \mathrm{~mm}$ below the heating surface. A copper block was heated to $300^{\circ} \mathrm{C}$ by applying a.c. current supplied from an a.c. power supply, and film boiling was established on the heater as water level was increased above the heater. Then film-boiling heat flux and heater temperature under steady-state conditions were measured by reducing electric power step by step to the minimum film boiling point - MHF point- Once the boiling heat transfer was immediately below the MHF point, namely, the temperature of the test section decreased steeply, the electric power to the cartridge-heater in the test section was increased. The voltage to the heater was controlled while monitoring the boiling surface temperature on a digital oscilloscope, and transition boiling in a "time-smoothed" steady state was achieved. Again transition-boiling heat flux and heater temperature under the respective steady-state conditions were measured by increasing electric power step by step to the critical heat flux and nucleate boiling. To confirm whether there is hysteresis in the boiling curve, heating experiments were also performed: the electric power to the cartridge heaters embedded in the test section was increased stepwise while maintaining nucleate boiling at the critical heat flux. Once the boiling heat transfer was immediately below the CHF point, namely, the temperature of the test section increased rapidly, the voltage to the cartridge-heater in the test section was slightly reduced. Electric power was controlled while monitoring boiling surface temperature on the digital oscilloscope. Transition boiling in a "time-smoothed" steady state in the heating mode was attained.

The criteria for transition boiling in a "timesmoothed" steady state are as follows.

(1) The temperature fluctuation inside $5 \mathrm{~mm}$ from the heating surface, where the thermocouple was the closest to the surface, should be within $2^{\circ} \mathrm{C}$.

(2) The temperature fluctuation at $25 \mathrm{~mm}$ position should be below $1.2^{\circ} \mathrm{C}$.

(3) The temperature fluctuation at the $45 \mathrm{~mm}$ position should be below $0.3^{\circ} \mathrm{C}$.

(4) Both above-mentioned conditions should be kept for more than $5 \mathrm{~min}$.

The wall heat flux and wall temperature of the test section were determined using measured temperatures and Fourier's law. The surface of the test section was polished with \#2000 or \#80 emery paper and cleaned with acetone prior to each experiment. During the experiments, the behaviors of the bubbles and liquid-vapor interface were recorded with a high-speed video-camera system. Furthermore, the void fraction near the boiling surface is measured using a pulse generator and a conductive probe located 0.2 to $0.5 \mathrm{~mm}$ above from the surface.

More details of the experimental apparatus and procedure can be found in Ref. (9).

\subsection{Stable conditions for steady transition boiling}

In general, steady transition boiling experiments are difficult, because of a negative gradient $(d q / d T<0)$ in the transition boiling region. However, data of steady transition boiling is obtained using a heating block with a large heat capacity in a previous study by other investigators ${ }^{(8)}$. Thus, we checked stable conditions for steady transition boiling using a three-dimensional transient heat conduction model. The procedure is as follows.

( 1 ) A temperature distribution under prescribed transition boiling conditions is calculated three-dimensionally in a block; the calculated method used is the same as that in section 4.1 .

(2) Then, a temperature disturbance is added on the heating surface. Here, the temperature disturbance is $2^{\circ} \mathrm{C}$, which is similar to the criterion for the transition boiling in a "time-smoothed" steady state. The parameters of the present simulation are the thickness of the heated block and the initial wall temperature.

( 3 ) If the temperature distribution is returned to the initial temperature, a steady transition boiling point is attained. In the simulation, the relationship between wall heat flux and wall superheat has a negative gradient.

Figure 3 shows conditions for steady transition boiling realized using the present simulation. From Fig. 3, the calculation results for the thickness of the present heater, $60 \mathrm{~mm}$, is covered under the stable condition for steady transition boiling up to low wall superheat. Therefore, steady transition boiling may be realized using the present heater. In addition, when the heated block is thin, the realized conditions for steady transition boiling are limited.

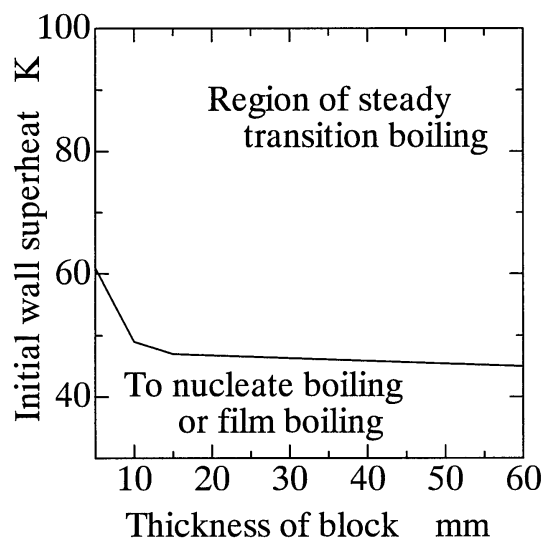

Fig. 3 Region of steady transition boiling by heat conduction model 


\subsection{Experimental uncertainty}

The temperature of the test section was measured using calibrated K-type thermocouples. According to the calibration curves, the uncertainty of the temperature was estimated to be less than $1 \mathrm{~K}$. Because the temperature gradient was about $150 \mathrm{~K}$ divided by $40 \mathrm{~mm}$ at the critical heat flux, the uncertainty of the critical heat flux obtained by Fourier's law was calculated to be about 5\%; the uncertainty at the minimum heat flux was estimated to be about $15 \%$ according to a temperature gradient of about $4 \mathrm{~K}$ divided by $40 \mathrm{~mm}$ at the minimum heat flux. Heat loss through the insulation was measured to be about $10 \%$ at CHF and about $25 \%$ at MHF. When the temperatures in the test block are measured, the linearity of the temperature distribution is confirmed well. The uncertainty of the liquid-solid contact fraction obtained from CHF, MHF and heat flux in transition boiling was estimated to be $20 \%$ through repeated experiments.

\section{Experimental Results and Discussion}

\subsection{Heat transfer characteristics - Boiling curve -}

In Fig. 4, our previous experimental results ${ }^{(7)}$ of the heat fluxes $q_{w}$ obtained during some steady-state experiments are plotted against wall superheat, $\Delta T_{s a t}=T_{w}-$ $T_{\text {sat }}$, for various experimental parameters such as surface roughness and type of heating procedure, namely heating mode or cooling mode. The conventional correlations for nucleate boiling ${ }^{(3)}$, critical heat flux $^{(10)}$ and film boiling ${ }^{(11)}$ are included for comparison. Figure 4 also shows the experimental results of steady-state transition boiling (cooling mode) reported by Bui and $\mathrm{Dhir}^{(8)}$ without special control systems. The data for the cooling mode were obtained using a test section with $7.4 \times 10^{5} \mathrm{~J} / \mathrm{Km}^{2}$ in $\rho c \mathrm{~V} / \mathrm{A}$.

As mentioned in our previous report ${ }^{(7)}$, the experimental results of boiling heat transfer are close to results calculated using the conventional correlations of sat-

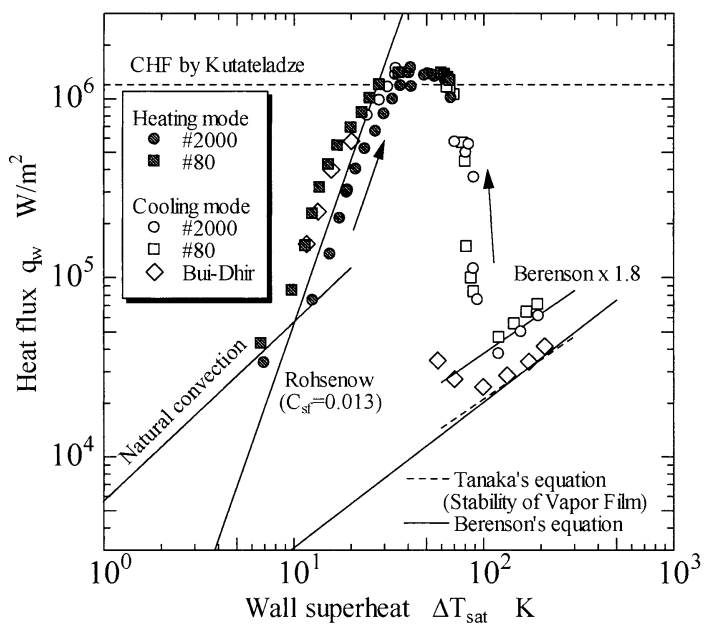

Fig. 4 Boiling curves for water urated pool boiling by Rohsenow ${ }^{(3)}$ for nucleate boiling, Kutateladze $^{(10)}$ for CHF, and Brenson ${ }^{(11)}$ for film boiling. Although the effect of surface roughness on nucleateboiling heat transfer is strong, the effect on transitionboiling heat transfer is weak. There is no hysteresis on transition boiling in the present experiments for water. The trend is similar to the experimental results of Auracher et al. ${ }^{(6)}$ and Haramura ${ }^{(12)}$, but different from those of Witte-Lienhard ${ }^{(5)}$ and Liaw-Dhir ${ }^{(13)}$.

\subsection{Liquid-solid contact fraction}

\section{- Correlation -}

On the basis of reports by Berenson ${ }^{(1)}$ and Kalinin et al. ${ }^{(2)}$, we examined the correlations of liquid-solid contact fractions in the transition boiling, $\Gamma$, as reported in our previous study ${ }^{(7)}$. The heat transfer in the wet region is given at the CHF to avoid overestimated heat flux in high superheat: for example, according to Rohsenow's correlation, the boiling heat transfer at a high superheat, $\Delta T_{\text {sat }}=100 \mathrm{~K}$, is $4.2 \times 10^{7} \mathrm{~W} / \mathrm{m}^{2}$. The heat transfer in the dry-out region is estimated at the MHF for convenience to utilize the present correlation. Thus, the liquid-solid contact fraction $\Gamma$ is derived using

$$
q_{t b}=q_{C H F} \Gamma+q_{M H F}(1-\Gamma) \rightarrow \Gamma=\frac{q_{t b}-q_{M H F}}{q_{C H F}-q_{M H F}},
$$

where, $q_{C H F}$ and $q_{M H F}$ are the measured heat fluxes at CHF and MHF, respectively. $q_{t b}$ is also the measured heat flux in transition boiling. Figure 5 shows the liquid-solid contact fraction plotted against dimensionless wall temperature, $\theta=\left(\Delta T_{\text {sat }}-\Delta T_{C H F}\right) /\left(\Delta T_{M H F}-\Delta T_{C H F}\right)$, for water, R113 and liquefied nitrogen under saturated condition. The experimental data for water were reported in our previous study ${ }^{(7)}$. The $\Gamma$ values for R-113 and $\mathrm{LN}_{2}$ are calculated using the experimental data reported by Haramura ${ }^{(12)}$ and Peyayopanakul and Westwater ${ }^{(14)}$, respectively.

The following correlation is obtained to provide an optimal agreement with the several experimental data from Fig. 5.

$$
\Gamma=1.000-0.9120 \theta-0.1343 \theta^{2} .
$$

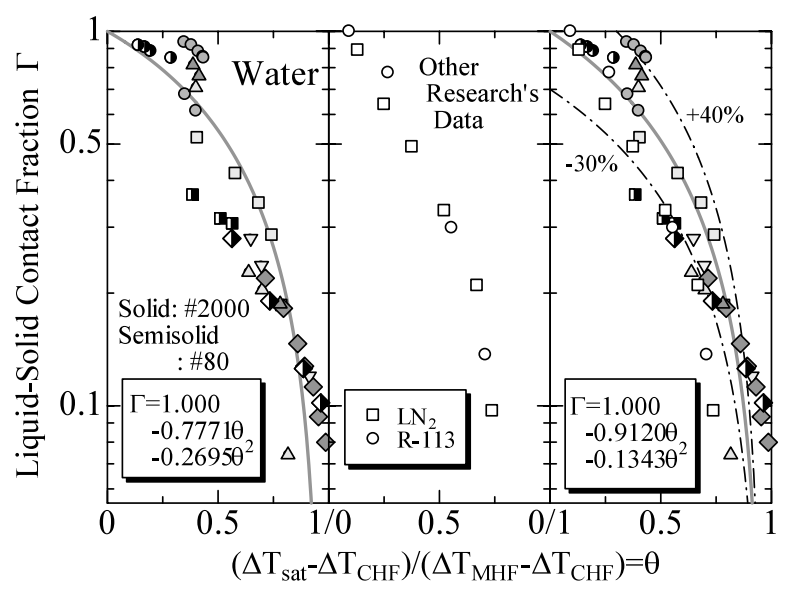

Fig. 5 Liquid-solid contact fraction based on CHF and MHF 


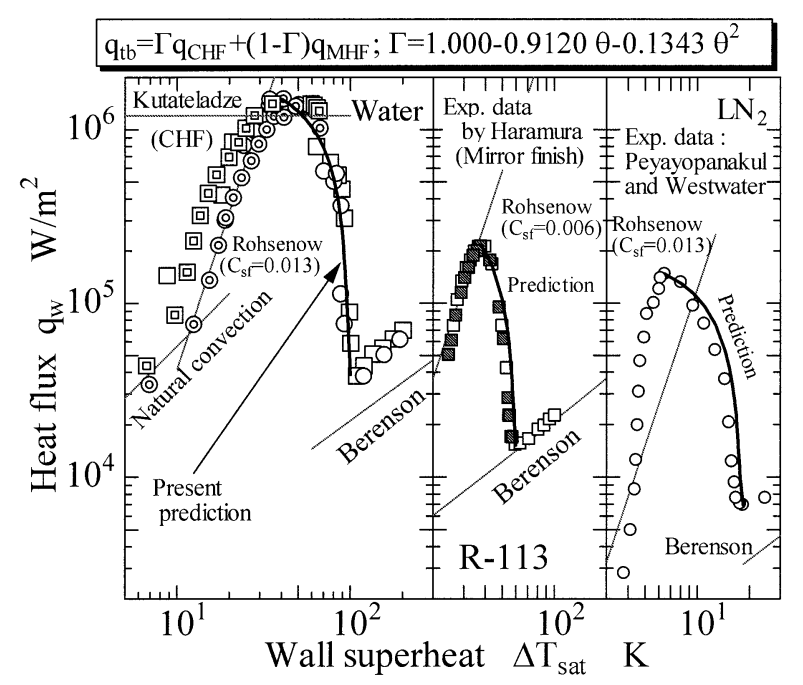

Fig. 6 Comparison with correlation and experimental results

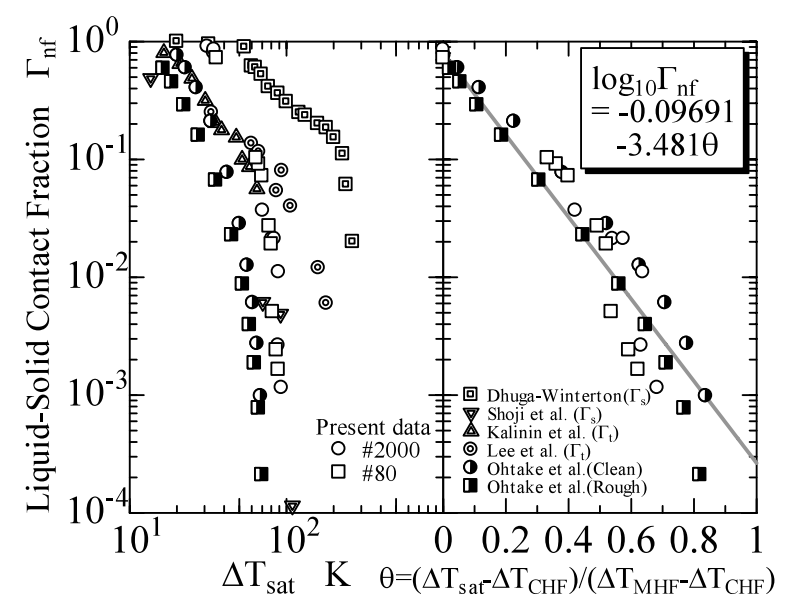

Fig. 7 Liquid-solid contact fraction based on nucleate boiling and film boiling ${ }^{(7)}$

Figure 5 also shows the accuracy of Eq. (2). Equation (2) is proposed, it has an accuracy of $40 \%$ for steady-state pool transition boiling on a clean surface in saturated liquid at atmospheric pressure.

Figure 6 shows the predicted transition-boiling heat transfers calculated using Eq. (2) and measured transitionboiling heat transfers at CHF and MHF for water, R-113 liquid and liquefied nitrogen. For R-113 liquid, the experimental data were reported by Haramura ${ }^{(12)}$ for steadystate experiments with a special control system. The experimental results for liquefied nitrogen were obtained by Peyayopanakul and Westwater ${ }^{(14)}$. The transitionboiling heat transfer calculated using the present correlation agrees well with the experimental results for each liquid, quantitatively. This result suggests that the prime dominant factor on transition-boiling heat transfer is wall superheat.

The conventional liquid-solid contact fraction, $\Gamma_{n f}=$ $\left(q_{t b}-q_{f b}\right) /\left(q_{n b}-q_{f b}\right)$, is also examined, as shown in Fig. 7 . As described previously ${ }^{(7)}$, however, the predictions for

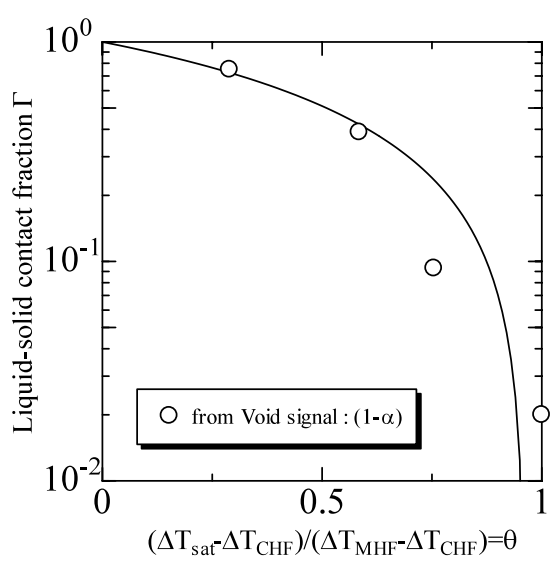

Fig. 8 Comparison with $\Gamma$ and $1-\alpha$

water are poorer than those obtained using Eq. (2). Here, $q_{n b}$ and $q_{f b}$ ate values calculated using Rosenow's correlation and Brenson's equation, respectively.

Thus, to estimate quantitatively the transition-boiling heat transfer, we recommend the revised correlation, Eq. (2), based on $\Gamma, \mathrm{CHF}$ and MHF points.

\subsection{Void fraction near heating surface}

$1-\alpha$ is plotted against the present dimensionless wall superheat $\theta$ in Fig. 8. The quantity subtracts the measured void fraction from unity. For reference, the liquid-solid contact fractions calculated on the basis of heat transfer characteristics in the present experiments are also included in Fig. 8. The values obtained from the measured void fractions are similar to those obtained from the liquidsolid contact fractions obtained on the basis of the heat transfer characteristics in Fig. 5. 1- $\alpha$ is related to the time fraction occupied by the liquid near the heating surface, that is, the liquid-solid contact time fraction. Although further detailed measurement will require the liquid-solid contact time fraction and liquid-solid contact space fraction in the transition-boiling region, it is considered from the analogy that the liquid-solid contact fraction is an Ergodic property in time and space.

\section{Modeling and Discussion}

\subsection{First model}

In our previous study ${ }^{(7)}$, we proposed and discussed a model of transition-boiling heat transfer in high superheat, focusing on heat conduction right after pseudo-liquid solid contact.

We considered that the pseudo-liquid solid contact right after detachment of a bubble from the liquid-vapor interface resulted from Rayleigh-Taylor instability, and analyzed transient heat conduction in it three dimensionally, as shown in Fig. 9. As all parameters for the liquidsolid contact were not clear, we selected appropriate values and examined the model by parametric simulations. The following conditions were adopted in the present model. 


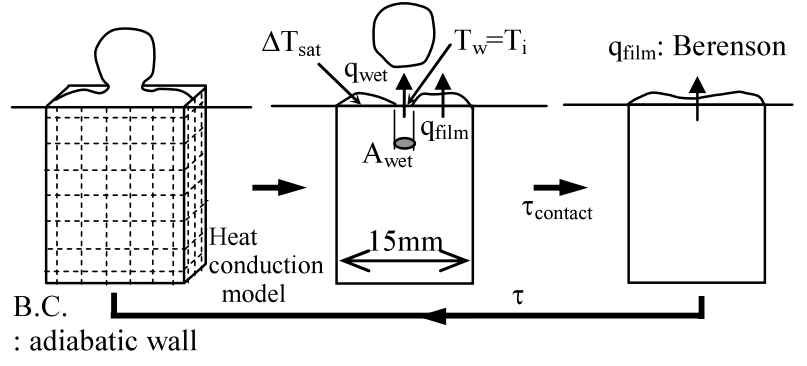

Fig. 9 Model of transition boiling at high superheat

(1) The period of pseudo-liquid solid contact, $\tau$, is $3 \mathrm{~Hz}(0.3 \mathrm{~s})$, because a bubble from a vapor film in film boiling is released every $0.3 \mathrm{~s}$.

(2) The time during the liquid-solid contact, $\tau_{\text {contact }}$, was $0.1 \mathrm{~s}$.

(3) The calculated region was $15 \mathrm{~mm} \times 15 \mathrm{~mm} \times$ $15 \mathrm{~mm}$.

(4) To take the effect of wetting into account, we used a wall temperature obtained right after the pseudoliquid solid contact given by

$$
\begin{aligned}
& T_{i}=\left(T_{w}+\beta T_{\text {sat }}\right) /(1+\beta), \\
& \text { where } \beta=\left\{(\rho c k)_{l} /(\rho c k)_{w}\right\}^{0.5},
\end{aligned}
$$

based on a two-body contact model. Heat flux in the wetted region was estimated by heat conduction from $T_{w}$ to $T_{i}$.

( 5 ) The transition-boiling heat transfer was obtained as a time space-averaged heat flux of the wetted and filmboiling areas.

( 6 ) The initial liquid-solid contact area, $A_{\text {wet }}$, was $1 \times$ $1,2 \times 2$ and $3 \times 3 \mathrm{~mm}^{2}$, respectively.

The predictions using the above model are shown in Fig. 10. As shown in Fig. 10, although the dependence on wall superheat of the predictions differs from that of the experimental data, if the wetted area increases with decreasing wall superheat, the dependence of transition boiling heat transfer on wall superheat supports the experimental results.

\section{2 Present model}

In the present report, the liquid-solid contact model of transition boiling heat transfer at a high wall superheat is developed by taking into account the dependence on wall superheat of liquid-solid contact time and area. Considering pseudo-liquid solid contact right after the detachment of a bubble from the liquid-vapor interface, transient heat conduction is also analyzed in it three-dimensionally. Liquid-solid contact time and area are given by the present correlation of the fractions of liquid-solid contact, Eq. (2).

When we assume that the liquid-solid contact time fractions are the same as the liquid-solid contact area fractions, some of the previous assumptions are replaced by the following relations.

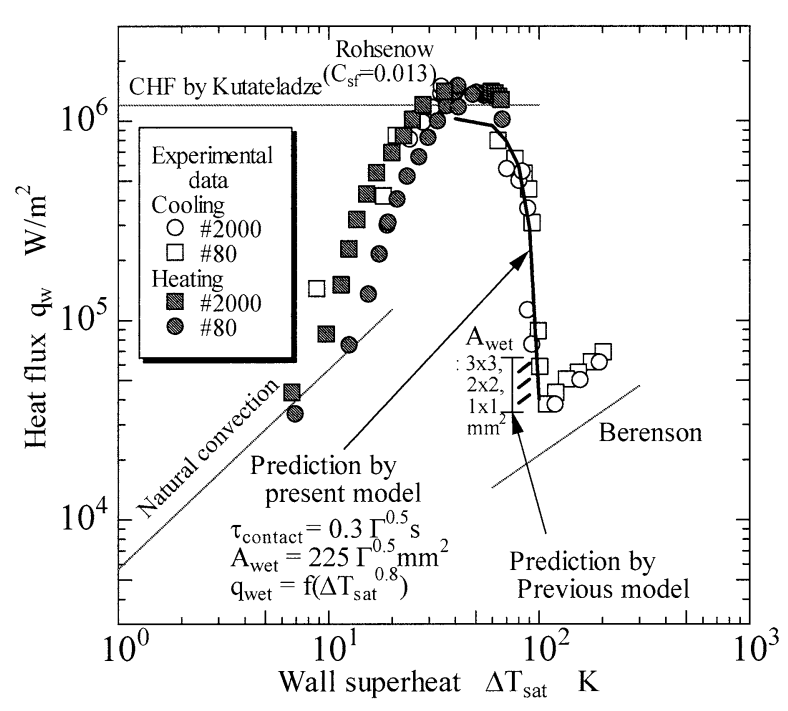

Fig. 10 Comparison between models and experimental results

for assumption (2), $\tau_{\text {constant }}=0.3 \Gamma_{t}=0.3 \Gamma^{0.5}[\mathrm{~s}]$

for assumption (6), $A_{w e t}=15 \times 15 \times \Gamma_{a}=225 \Gamma^{0.5}\left[\mathrm{~mm}^{2}\right]$

$$
\text { where } \begin{aligned}
\Gamma & =\Gamma_{t} \times \Gamma_{a}=1.000-0.9120 \theta-0.1343 \theta^{2} \\
\theta & =\left(T_{w}-T_{C H F}\right) /\left(T_{M H F}-T_{C H F}\right)
\end{aligned}
$$

Furthermore, heat transfer during the wet period is taken into account in this report.

$$
\begin{aligned}
& \text { for } t<t_{\text {wait }}, q=q_{\text {conduciotn to liquid }} \\
& \text { for } t>t_{\text {wait }}, q=q_{\text {wet }}=f\left(\Delta T_{\text {sat }}{ }^{0.8}\right)
\end{aligned}
$$

The latter is Shoji's correlation ${ }^{(15)}$ during the wet period. Here, the waiting time by incipient boiling, $t_{\text {wait }}$, is estimated using

$$
t_{\text {wait }}=\left(1 / \pi \alpha_{l}\right)\left\{R_{c} \Delta T_{\text {sat }} /\left(\Delta T_{\text {sat }}-\Delta T_{B I}\right)\right\}^{2} .
$$

$R_{c}$ is the radius of an active cavity for any superheat.

$$
\frac{R_{c}}{\sin \phi}=\frac{2 \sigma\left(\rho_{l}-\rho_{v}\right) T_{\text {sat }}}{\rho_{l} \rho_{v} L \Delta T_{\text {sat }}\left\{1-\frac{h}{k_{l}} \frac{R_{c}}{\sin \phi}(1+\cos \phi)\right\}}
$$

$\Delta T_{B I}$ is the liquid superheat of an active spherical bubble with a radius of $R_{e}\left(=R_{c} / \sin \phi\right)$ in a uniform temperature field.

$$
\Delta T_{B I}=\frac{2 \sigma\left(v_{v}-v_{l}\right) T_{s a t}}{L R_{e}}
$$

In Eq. (9), $\phi$ is the contact angle, which is $90^{\circ}$ for the present model. $h$ is natural-convection heat transfer coefficient obtained by the present experiments (see Fig. 4).

Figure 10 also shows the prediction by the present model. The prediction by the present model agrees well with the present experimental data for water in the transition boiling region, both qualitatively and quantitatively. 


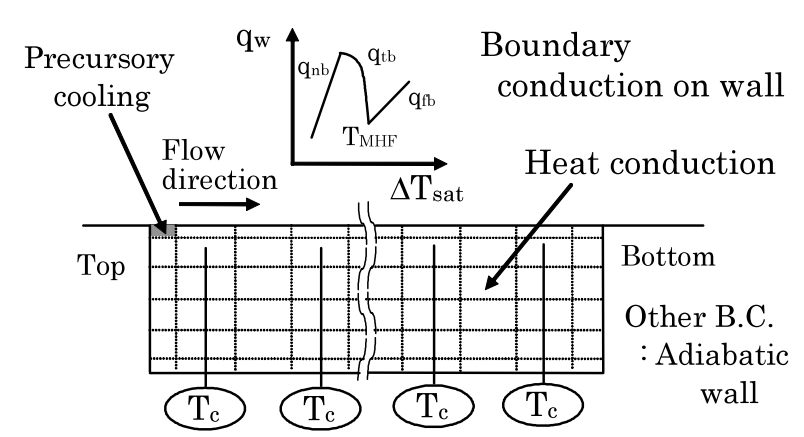

(a) Correlation model (Side view)

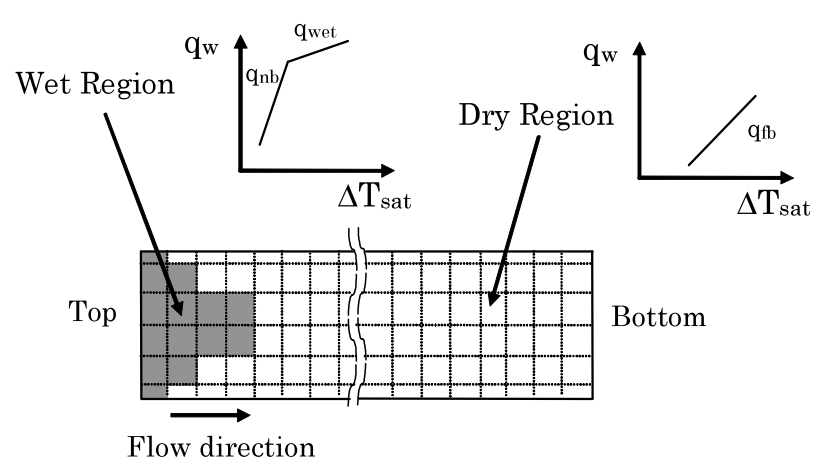

(b) Wetting model (Top view)

Fig. 11 Rewetting models

\subsection{Application to rewetting}

In this section, the simulation of rewetting ${ }^{(16)}$ is performed using two transient heat conduction models with the present correlation of transition boiling heat transfer and the present liquid-solid contact model. As in Ref. (16), we use the pool boiling heat transfer characteristics as the boundary conditions of the heat transfer surface because the heat transfer characteristics during the rewetting of the falling film in the film flow rate range from 0.096 to $0.639 \mathrm{~kg} / \mathrm{ms}$ at atmospheric pressure were similar to those during conventional pool boiling.

4.3.1 Correlation model The following assumptions were employed for the present correlation of transition boiling heat transfer.

(1) The two-dimensional transient heat conduction is applied in a slab (see Fig. 11).

For boundary conditions on heating surface, the following are noted.

(2) The heat flux in the dry region $q_{f b}$ is calculated using Bromley's equation.

(3) The MHF point $T_{M H F}$ is determined using Nishio's equation ${ }^{(17)}\left(200^{\circ} \mathrm{C}\right)$.

(4) The heat flux in the region after rewetting, $q_{t b}$, is estimated using the present transition boiling correlation

$$
\begin{aligned}
& q_{t b}=q_{C H F} \Gamma+q_{M H F}(1-\Gamma), \\
& \text { where } \Gamma=1.000-0.9120 \theta-0.1343 \theta^{2}, \\
& \quad \theta=\left(T_{w}-T_{C H F}\right) /\left(T_{M H F}-T_{C H F}\right) .
\end{aligned}
$$

(5) The heat flux in the wetted region $q_{n b}$ is found using Rohsenow's correlation.

(6) A portion of the upper boundary on the heating surface is initially $q_{C H F}$ given by Kutatelaze's equation, because of precursory cooling.

( 7 ) The other boundary conditions except for the heating surface are adiabatic walls.

4.3.2 Wetting model The following assumptions are used in simulating the present liquid-solid contact model.

(1) "Three"-dimensional transient heat conduction is applied in the slab.

For the boundary conditions on heating surface, the following are noted.

(2) The heat flux in the dry region, $q_{f b}$, is calculated using Bromley's equation.

(3) The heat flux in the wetted region $q_{n b}$ is determined using Shoji's correlation: $f\left(\Delta T_{\text {sat }}^{0.8}\right)$.

(4) Once the wall is wet, the wetted region is maintained: $\Gamma_{t}=1$.

( 5 ) The wetted area is estimated with the liquid-solid contact fraction $\Gamma$ :

$$
\begin{aligned}
& \Gamma_{a}=1.000-0.9120 \theta-0.1343 \theta^{2}, \\
& \text { where } \theta=\left(T_{w}-T_{C H F}\right) /\left(T_{M H F}-T_{C H F}\right) .
\end{aligned}
$$

(6) During precursory cooling, a portion of the upper boundary on the heating surface is initially $q_{C H F}$ given by Shoji's equation $^{(15)}$.

(7) The other boundary conditions except for the heating surface are adiabatic walls.

4.3.3 Calculation results and discussion Some predictions by the rewetting model are illustrated in Fig. 12. The cooling curves obtained in an experiment on rewetting of a vertical hot thick surface using a falling film $^{(16)}$ are also shown in Fig. 12. As seen from Fig. 12, the experimental cooling curves obtained during the rewetting are well reproduced by the transient heat conduction models using the present correlation of transition boiling heat transfer and the present liquid-solid contact model.

\section{4 Application to core cooling}

In the following sections, the present correlation described in the previous section is examined for application to core cooling including wettability on a heated surface.

Figure 13 shows the measurement results of a transient boiling experiment for water in a 12.5 -mm-ID inconel X-750 tube at a mass flux of $135 \mathrm{~kg} / \mathrm{m}^{2} \mathrm{~s}$, a quality of 0.49 and a pressure of $6.90 \mathrm{MPa}$. The experimental data were reported by Iloeje et al. ${ }^{(18)}$ The prediction of transition-boiling heat transfer calculated using the present correlation, Eq. (2), is also plotted in Fig. 13. The prediction by the present correlation of transition boiling 


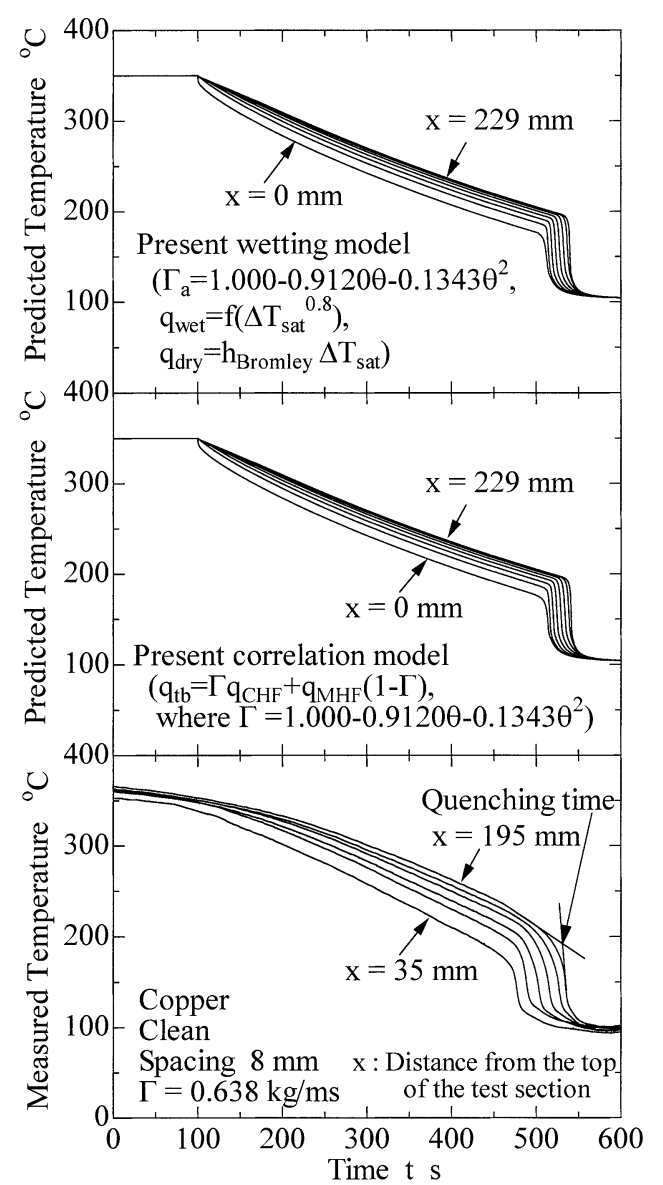

Fig. 12 Comparison between experimental data and some simulation results during rewetting

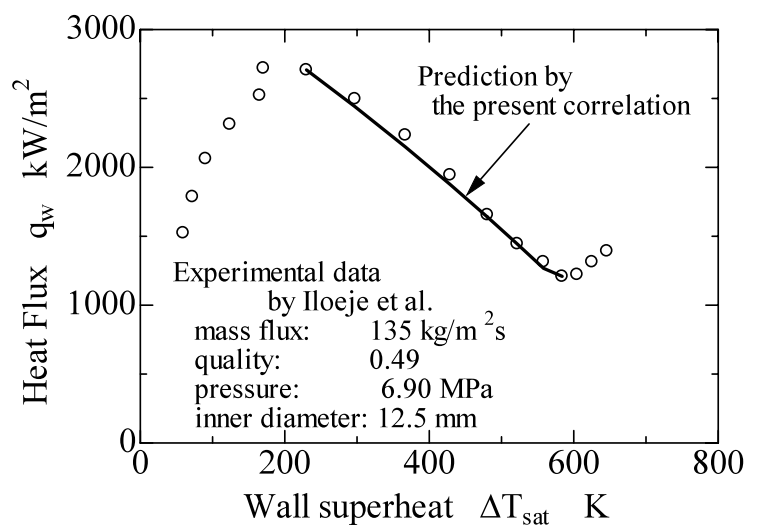

Fig. 13 Comparison between present correlation and experimental results for conditions similar to those of core cooling

heat transfer describes well the experimental results for conditions similar to those for core cooling, as shown in Fig. 13. More detailed examinations are expected using some analysis codes with the present correlation to assess the characteristics of core cooling.

To examine the effect of wettability on transition boiling heat transfer, Fig. 14 shows the measurement boiling curve obtained during rewetting using a falling film for

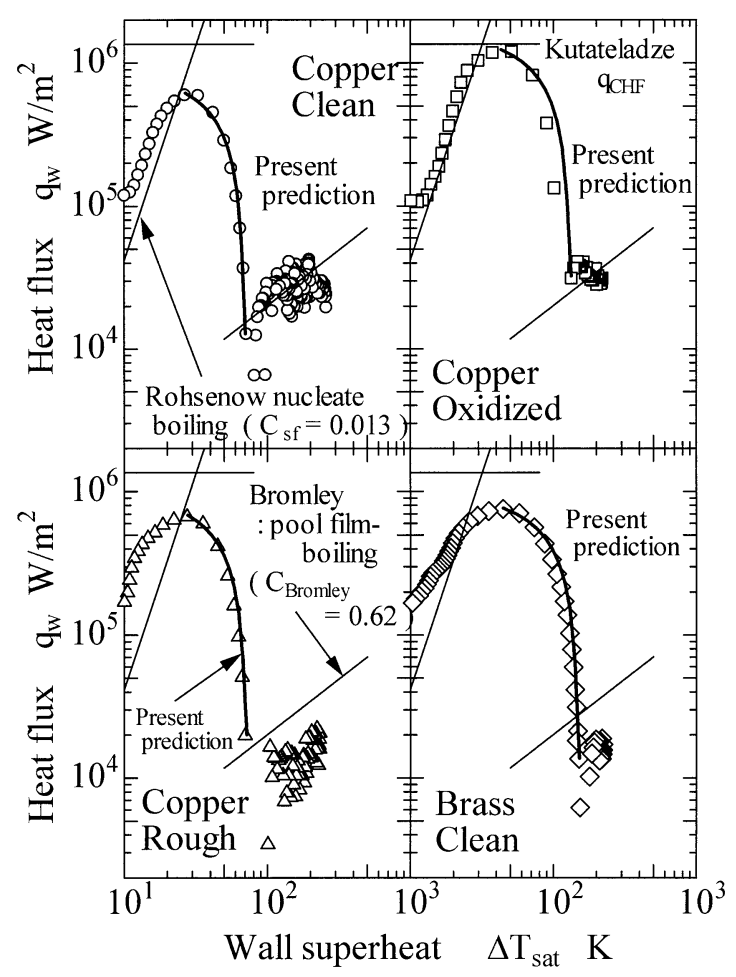

Fig. 14 Comparison between present correlation and experimental results for wettability

saturated water in copper and brass slabs in the film flow rate range of 0.096 to $0.639 \mathrm{~kg} / \mathrm{ms}$. The experimental data were reported by us ${ }^{(16)}$. The test parameter is wettability on a heated surface. We examined the dependence of wettability of different surfaces (namely, copper clean surface, copper oxidized surface, copper rough surface and brass clean surface) on transition boiling heat transfer. The predictions of transition-boiling heat transfer calculated using the present correlation, Eq. (2), are also plotted in Fig. 14. The predictions by the present correlation of transition boiling heat transfer agree well the experimental results including the dependence of wettability on transition boiling heat transfer, as shown in Fig. 14. Although further examination is required, the finding suggests that critical heat flux, minimum heat flux and their superheats reflect wettability. When we examine closely, there is a small difference between the measured and calculated heat fluxes for experimental condition of the copper oxidized surface. Further collection of many experimental data is required for oxidized surfaces to accurately assess the dependence of wettability on transition boiling heat transfer.

Transition boiling heat transfer was well reproduced by the present correlation for some clean metal surfaces and several liquids (namely, water, R-113 and liquefied nitrogen).

\section{Conclusions}

Transition boiling heat transfer was examined by deriving the correlation and model, the following conclu- 
sions were obtained.

(1) As correlation of transition boiling heat transfer,

$$
\Gamma=1.000-0.9120 \theta-0.1343 \theta^{2}
$$

was presented from experimental results for water, R-113 and $\mathrm{LN}_{2}$. Here, heat flux in transition boiling was given by $q_{t b}=q_{C H F} \Gamma+q_{M H F}(1-\Gamma) . \theta$ is the dimensionless temperature: $\theta=\left(T_{w}-T_{C H F}\right) /\left(T_{M H F}-T_{C H F}\right)$. Transition boiling heat transfer was well reproduced by the present correlation for some clean metal surfaces and several liquids (namely, water, R-113 and liquefied nitrogen).

(2) The prediction by the present model, taken the dependence on wall superheat of liquid-solid contact time and area into account using the present correlation and nucleate boiling heat transfer during the wet period, agreed well with the present experimental data for water in the transition boiling region, both qualitatively and quantitatively.

(3) A simulation of rewetting was performed using the present transition boiling correlation and model; the experimental cooling curves during rewetting were well reproduced by the transient heat conduction model using the present correlation of transition boiling heat transfer and the present liquid-solid contact model.

\section{Acknowledgments}

The authors acknowledge the support for this study in the form of a research fund (Grant-in Aid for Scientific Research (c), No. 11650235) from the Ministry of Education, Culture, Sports, Science and Technology of Japan.

\section{References}

(1) Berenson, P.J., Experiments on Pool-Boiling Heat Transfer, Int. J. Heat Mass Transf., Vol.5 (1962), pp.985-999.

( 2 ) Kalinin, E.K., Berlin, I.I. and Kostiouk, V.V., Transition Boiling Heat Transfer, Adv. Heat Transf., Vol.18 (1987), pp.241-323.

( 3 ) Rohsenow, W.M., A Method of Correlating HeatTransfer Data for Surface Boiling of Liquids, Trans. ASME, J. Heat Transf., Vol.74 (1952), pp.969-975.

( 4 ) Bromley, L.A., Heat Transfer in Stable Film Boiling, Chem. Eng. Prog., Vol.58, No.5 (1950), pp.221-227.

( 5 ) Witte, L.C. and Lienhard, J.H., On the Existence of Two 'Transition' Boiling Curves, Int. J. Heat Mass Transf., Vol.25 (1982), pp.771-779.

( 6 ) Auracher, H., Marquardt, W., Buchholz, M., Hohl, R.,
Luttich, T. and Blum, J., New Experimental Results on Steady-State and Transient Pool Boiling Heat Transfer, Thermal Science \& Engineering, Vol.9 (2001) pp.2939.

( 7 ) Ohtake, H., Hongo, H. and Koizumi,Y., Derivations of Correlation and Model of Transition Boiling Heat Transfer, CD-ROM the 6th ASME-JSME Thermal Engineering Joint Conference, TED-AJ03-319 (2001), pp.1-7.

( 8 ) Bui, T.D. and Dhir, V.K., Transition Boiling Heat Transfer on a Vertical Surface, Trans. ASME, J. Heat Transf., Vol.107, No.4 (1985), pp.756-763.

( 9 ) Hongo, H., Derivations of Correlation and Model of Transition Boiling Heat Transfer, Master Thesis, Kogakuin University, Tokyo, Japan, (in Japanese), (2002).

(10) Kutateladze, S.S., Heat Transfer in Condensation and Boiling, AEC-tr-3770, (1952).

(11) Berenson, P.J., Film-Boiling Heat Transfer from a Horizontal Surface, Trans. ASME, J. Heat Transf., Vol.83 (1961), pp.351-358.

(12) Haramura, Y., Steady State Pool Transition Boiling Heated with Condensing Steam, ASME/JSME Thermal Engineering Proc., Vol.2 (1991), pp.59-64.

(13) Liaw, S.P. and Dhir, V.K., Effect of Surface Wettability on Transition Boiling Heat Transfer from a Vertical Surface, Proc. 8th Int. Heat Transf. Conf., Vol.4 (1986), pp.2031-2036.

(14) Peyayopanakul, W. and Westwater, J.W., Evaluation of the Unsteady-State Quenching Method for Determining Boiling Curves, Int. J. Heat Mass Transf., Vol.21 (1978), pp.1437-1445.

(15) Shoji, M., Yokoya, S. and Huang, Z.L., A Study of Transition Boiling Heat Transfer (Steady Boiling of Water on a Horizontal Copper Surface), Trans. Jpn. Soc. Mech. Eng., (in Japanese), Vol.58, No.551, B (1992), pp.2214-2220.

(16) Ohtake, H. and Koizumi, Y., Study on Rewetting of Vertical-Hot-Thick Surface by a Falling Film (Investigation from the Aspect of Boiling Heat Transfer Characteristics and Modeling), 11th Int. Heat Transf. Conf., Vol.2 (1998), pp.325-330.

(17) Nishio, S., Prediction Technique for Minimum-HeatFlux(MHF)-Point Condition of Saturated Pool Boiling, Int. J. Heat Mass Transf., Vol.30, No.10 (1987), pp.2045-2057.

(18) Iloeje, O.C., Plummer, D.N., Rohsenow, W.M. and Griffith, P., An Investigation of the Collapse and Surface Rewet in Film Boiling in Forced Vertical Flow, Trans. ASME, J. Heat Transf., Vol.97, No.2 (1975), pp.166-172. 